\title{
Dose inseminante para fertilização artificial de ovócitos de jundiá cinza, Rhamdia Quelen (Quoy \& Gaimardm, 1824)
}

\section{Robie Allan Bombardelli ${ }^{1}$, Eder Felipe Mörschbächer², Rodrigo Campagnolo², Eduardo Antônio Sanches ${ }^{3}$, Mirna Adriane Syperreck ${ }^{4}$}

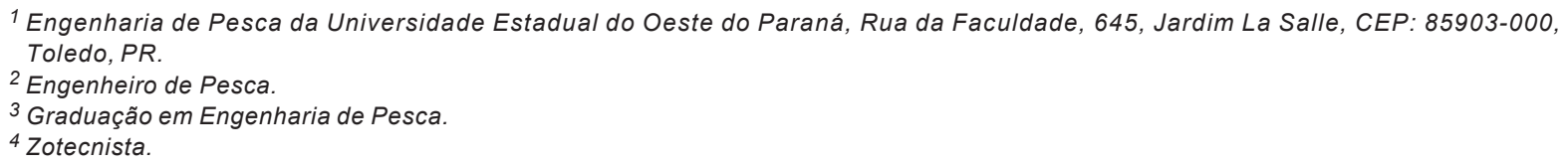

RESUMO - Para determinação da dose inseminante ideal na fertilização artificial de ovócitos de jundiá cinza (Rhamdia quelen), foram selecionadas duas fêmeas com papila urogenital avermelhada, abdômen arredondado e liberação de ovócitos de cor e tamanho uniforme e quatro machos que apresentavam liberação de sêmen sob pressão da papila genital. As fêmeas e os machos receberam duas doses de extrato de hipófise de carpa (doses inicial e final de 0,5 e $0,25 \mathrm{mg} \cdot \mathrm{kg}^{-1}$ e de 5,0 e $2,5 \mathrm{mg} \cdot \mathrm{kg}^{-1}$, para fêmeas e machos, respectivamente). As duas fêmeas produziram $169 \mathrm{~g}$ de ovos contendo 1.141 ovócitos.g de ovócitos ${ }^{-1}$ e os machos, um total de $23,6 \mathrm{~mL}$ de sêmen. Do sêmen dos quatro machos foi realizado um pool e analisadas as seguintes características: concentração espermática $\left(1,97 \times 10^{10}\right.$ espermatozóides.mL $\left.\mathrm{mL}^{-1}\right)$, índice de sobrevivência espermática (96\%) e morfologia espermática $(66,9 \%$ de espermatozóides normais). No ensaio de fertilização, utilizou-se delineamento experimental inteiramente casualisado, composto de cinco tratamentos $\left(6 \times 10^{3}, 6 \times 10^{4}, 6 \times 10^{5}, 6 \times 10^{6}, 2 \times 10^{7}\right.$ espermatozóides.ovócito-1 $)$ e quatro repetições. Após 8 horas de incubação, foram analisadas as taxas de fertilização para cada tratamento. A melhor relação espermatozóide.ovócito ${ }^{-1}$ foi de 89.497 espermatozóide.ovócito-1, o que provocou taxa de fertilização máxima teórica de $86,68 \%$.

Palavras-chave: dose inseminante, reprodução, Rhamdia quelen

\section{Insemination dose for artificial fertilization of grey jundia oocytes, Rhamdia quelen (Quoy \& Gaimardm, 1824)}

\begin{abstract}
Two females with colored urogenital organ, rounded off abdomen, color egg released, and uniform size and four males with semen released under abdomen pressure were selected to determine the best insemination dose for artificial fertilization of grey jundia, Rhamdia quelen (Quoy \& Gaimardm, 1824), oocytes. Females and males received two doses of carp pituitary extract: the first one of 0.5 and $0.25 \mathrm{mg} \cdot \mathrm{kg}^{-1}$ and the second of 5.0 and $2.5 \mathrm{mg} \cdot \mathrm{kg}^{-1}$ for females and males, respectively. Both females produced $169 \mathrm{~g}$ of eggs with 1,141 oocytes.oocytes $\mathrm{g}^{-1}$. The males produced a total of $23.6 \mathrm{~mL}$ of semen. From all males semen pool sperm concentration $\left(1.97 \times 10^{10}\right.$ spermatozoa.mL $\left.L^{-1}\right)$, survival sperm index $(96 \%)$ and sperm morphology were analyzed $(66.9 \%$ of normal spermatozoa). The fertilization assay was conducted as a complete randomized experimental design with five treatments $\left(\left(6 \times 10^{3}, 6 \times 10^{4}, 6 \times 10^{5}, 6 \times 10^{6}, 2 \times 10^{7}\right.\right.$ spermatozoa.oocyte $\left.^{-1}\right)$ and four replications. After eight hours of incubation, the fertilization rates for each treatment were analyzed. The best spermatozoa.oocyte ${ }^{-1}$ rate was of 89.497 spermatozoa.oocyte ${ }^{-1}$ that produced a maximum fertilization rate of $86.68 \%$.
\end{abstract}

Key Words: insemination dose, reproduction, Rhamdia quelen

\section{Introdução}

O jundiá cinza (Rhamdia quelen, Quoy \& Gaimard, 1824) é uma espécie de peixe pertencente à ordem Siluriforme e à família Pimelodidae (Nakatani et al., 2001), encontrada desde o sudoeste do México ao centro da Argentina (Silfvergrip, 1996; Baldisseroto, 2004).

Segundo Boscardin Borghetti et al. (2003), no ano 2000, foram produzidas 176.531 toneladas de pescado provenien- tes da aqüicultura, sendo 132.989 toneladas provenientes do cultivo de peixes. Considerando este perfil das diversas espécies de peixes nativas cultivadas no país, o jundiá (Rhamdia quelen) representou um total de produção de 2.546 toneladas no ano de 2000, o que correspondeu a 1,4\% do total produzido pelo setor aqüícola brasileiro (Boscardin Borghetti et al., 2003).

Esta espécie nativa de peixe apresenta grande importância econômica na Região Sul do Brasil, pois é, aparente- 
mente, bem adaptada a diferentes ambientes, amplamente utilizada nos viveiros de piscicultura e de boa aceitação no mercado consumidor (Marchioro \& Baldisserotto, 1999). O cultivo do jundiá vem crescendo progressivamente no sul do Brasil (Piaia \& Baldisseroto, 2000), pois esse peixe apresenta uma carne com ótimo sabor, textura e alto rendimento de carcaça (Ferreira et al., 2001). Além disso, tolera baixas temperaturas e apresenta bom crescimento no verão, em sistemas de cultivo, nos quais a uma densidade de 2 a 4 peixes $/ \mathrm{m}^{2}$ pode alcançar 600 a $800 \mathrm{~g}$ de peso em oito meses (Barcelos et al., 2003).

Além do bom desempenho produtivo, outro fator que favoreceu o destaque desta espécie na piscicultura brasileira foi o domínio do processo reprodutivo em cativeiro. Segundo Ferreira et al. (2001), estes animais podem iniciar a maturação gonadal em temperaturas a partir de $17^{\circ} \mathrm{C}$ e as desovas apresentam dois picos ao longo do ano, na primavera e no verão.

Apesar de a tecnologia da reprodução do jundiá estar praticamente dominada (Huergo, 2004), alguns aspectos relacionados à otimização do uso dos reprodutores ainda devem ser estudados, pois o sucesso de programas economicamente produtivos de inseminação artificial depende da máxima utilização dos gametas disponíveis, o que significa fertilizar o maior numero de ovócitos com a menor quantidade de espermatozóides (Fogli da Silveira et al., 1988; Billard et al., 1996), considerando-se a qualidade dos gametas femininos e masculinos (Rurangwa et al., 2004). Para isso, muito se tem feito para diluir o sêmen produzido por alguns reprodutores (Erdahl \& Graham, 1987).

A exemplo de alguns mamíferos como os bovinos, eqüinos, ovinos ou suínos, nos quais são empregadas doses inseminantes contendo uma concentração espermática correta para o máximo sucesso na fertilização, muitos pesquisadores têm determinado, em peixes, doses ideais de concentração de espermatozóides para cada ovócito a ser fertilizado. Estes estudos têm sido realizados a partir de sêmen fresco e/ou congelado, para Salmo irideus (Fogli da Silveira et al., 1988), Oreochromis spp. (Rana \& McAndrew, 1989), Scophthalmus maximus (Suquet et al., 1995), Latris lineata (Ritar, 1999), Salvelinus alpinus (Richardson et al., 2000), Silurus glanis (Linhart et al., 2004), Brycon insignis (Shimoda et al., 2004) e outras.

A técnica de inseminação artificial tem sido utilizada em fazendas de peixes, contudo, a sua eficiência apresenta limitações e variações acentuadas quanto aos resultados. Entre alguns dos fatores limitantes, pode-se considerar a qualidade dos gametas, avaliada por meio de parâmetros como as taxas de fertilização e eclosão, a motilidade e a con-centração espermática, exceto a relação espermatozóide: ovócito, que raramente é relatada (Rurangwa et al., 1998). A otimização desta última relação, além de melhorar significativamente as taxas de fertilização, possibilita economia de gametas, pois o esperma de um único macho poderia fertilizar um número maior que apenas 1 a 5 fêmeas (Marques, 2001).

Segundo Fogli da Silveira et al. (1988), a rotina de reprodução artificial com sêmen fresco ou congelado revela a possibilidade de limitar o estoque de machos na piscicultura intensiva, propiciando a exploração mais racional de reprodutores geneticamente selecionados e redução nos custos de produção.

São poucos os estudos que tratam de capacidade de fertilização de peixes. Este parâmetro pode variar entre espécies, pois vários fatores podem interferir no processo, entre eles, o tamanho do ovócito, a qualidade do ovócito, o tempo de motilidade espermática e a distância percorrida pelos espermatozóide (Suquet et al., 1995). O mesmo autor sugere ainda que cada reprodutor deve ter seus gametas analisados para determinar seu potencial ótimo de fertilização.

O conhecimento da correta relação espermatozóide: ovócito apresenta também grande importância para o desenvolvimento de programas de criopreservação (Ritar, 1999; Denniston et al., 2000) de sêmen e/ou ovócitos, destinados tanto para fins de conservação da biodiversidade genética de espécies como para o uso em programas de melhoramento genético em fazendas de cultivo.

Este trabalho foi conduzido com o objetivo de determinar a dose inseminante, ou relação espermatozóide.ovócito ${ }^{-1}$, adequada para fertilização artificial de ovócitos de jundiá cinza.

\section{Material e Métodos}

O trabalho foi conduzido no Centro de Pesquisas em Aqüicultura Ambiental - CPAA/IAP - Toledo/PR no mês de novembro de 2004. Os reprodutores provenientes de estações comerciais de cultivo foram estocados em um tanque escavado, revestido com concreto, fundo de terra e dimensão de $200 \mathrm{~m}^{2}$, sem renovação de água e com abastecimento somente para compensar a água evaporada e infiltrada. Os peixes foram alimentados com dieta comercial processada na forma extrusada e com $28 \%$ de PB. Para captura e seleção dos reprodutores dentro do tanque, foi utilizada uma rede de arrasto de malha $11 \mathrm{~mm}$. Foram selecionadas duas fêmeas que apresentavam abdômen arredondado, papila urogenital avermelhada e coloração e tamanho dos ovócitos uniformes e quatro machos que 
liberavam esperma sob leve pressão da papila urogenital, segundo Woynarovich \& Horvath (1983) e Baldisseroto (2004).

Os animais selecionados foram individualmente pesados, marcados e separados por sexo em dois tanques, dotados de aeração e renovação constante de água. Aplicou-se, em seguida, uma dose de $0,5 \mathrm{mg}$ de extrato de hipófise de carpa (EHC).kg de reprodutor ${ }^{-1}$ e $0,25 \mathrm{mg}$ EHC.kg de reprodutor ${ }^{-1}$ para as fêmeas e os machos, respectivamente. Doze horas após a primeira aplicação, foi aplicada uma segunda dose de $5 \mathrm{mg}$ EHC.kg de reprodutor ${ }^{-1}$ e 2,5 mg EHC.kg de reprodutor ${ }^{-1}$ para fêmeas e machos, respectivamente (intramuscular, na região dorsal).

Após as aplicações, a temperatura foi mantida em $22,0 \pm 1,0^{\circ} \mathrm{C}$ e monitorada freqüentemente.

A coleta dos gametas masculinos foi realizada após um período de 240 horas-grau ou unidades térmicas acumuladas (UTA), sendo os reprodutores contidos e secos com pano e papel toalha. Em seguida, foi aplicada individualmente massagem na região ventral do animal sempre no sentido encéfalo-caudal. A primeira gota de sêmen foi desprezada para evitar possível contaminação e o restante foi coletado a partir de um tubo Falcon, com graduação de $0,1 \mathrm{~mL}$, para mensuração do volume total do ejaculado e da produção relativa de sêmen.

$\mathrm{O}$ índice de sobrevivência dos espermatozóides foi analisado a partir do método de coloração de nigrosina eosina, segundo Kavamoto \& Fogli da Silveira (1986). Após o processamento das lâminas, o material foi analisado em microscópio de luz (400x). Foram contados 400 espermatozóides, sendo considerados vivos aqueles com coloração branca e mortos aqueles com coloração vermelha ou rosada (permeáveis ao corante).

A mensuração da concentração espermática do sêmen foi realizada a partir de um pool de sêmen dos quatro reprodutores. Em seguida, foi retirada uma amostra de $2 \mathrm{~mL}$ de sêmen e diluída em $4.000 \mathrm{~mL}$ de formol salina tamponado (5\%), resultando na diluição de 1:2000, analisada em câmara hematimétrica de Neubauer, segundo Mylonas et al. (1997).

Com o material fixado anteriormente, foram realizados dois esfregaços para avaliação e mensuração dos índices de alterações morfológicas dos espermatozóides, segundo Streit Jr. (2002) e Rurangwa et al. (2004). As lâminas foram submetidas à coloração em Rosa Bengala (Hafez \& Hafez, 2004) e analisadas em microscópio de luz (400x), observando-se um total de 400 espermatozóides por esfregaço.

Após 240 UTA, as fêmeas foram extrusadas de forma idêntica aos machos e seus ovócitos coletados em uma bacia seca e de peso conhecido. O peso total dos ovócitos liberados de cada fêmea foi mensurado em balança digital com capacidade para $1 \mathrm{~kg}$ e precisão de $0,01 \mathrm{~g}$. Do material coletado de ambas as fêmeas, formou-se um pool de ovócitos do qual foram retiradas três amostras de peso conhecido para estimativa do número relativo de ovócitos por grama de material liberado, por meio da pesagem em balança analítica com precisão de $0,0001 \mathrm{~g}$.

Determinado o numero relativo de ovócitos, foram pesadas, separadamente, 20 amostras de $3 \mathrm{~g}$ de ovócitos. A determinação da concentração espermática do sêmen foi realizada a partir de micro-pipetas de escala $0,5-5 \mathrm{~mL}$ e $100-1.000 \mathrm{~mL}$.

Para determinação da dose inseminante, misturaram-se ao sêmen $60 \mathrm{~g}$ de ovócitos, os quais, após a fertilização, foram distribuídos em 20 incubadoras experimentais confeccionadas em PVC, de formato cônico e volume útil de 2,5 L. Os ovócitos fertilizados foram distribuídos em um delineamento experimental inteiramente casualizado, composto decinco tratamentos e quatro repetições. Foi considerada uma unidade experimental uma incubadora de volume útil de 2,5 L, contendo $3 \mathrm{~g}$ de ovócitos fertilizados. Os tratamentos foram baseados em experimentos pilotos desenvolvidos previamente e constituídos pelas doses inseminantes ou pelas relações de número de espermatozóides.ovócito ${ }^{-1}$ de $6 \times 10^{3}, 6 \times 10^{4}, 6 \times 10^{5}, 6 \times 10^{6}, 2 \times 10^{7}$ espermatozóides.ovócito ${ }^{-1}$. Os tratamentos tiveram variação da ordem de grandeza de $1 \times 10^{1}$, de modo que, no último tratamento, utilizaram-se $2 \times 10^{7}$ espermatozóides.ovócito ${ }^{-1}$, em razão da limitação de volume de sêmen necessário.

Após a fertilização, a água das incubadoras foi mantida aquecida em $22,0 \pm 1,0^{\circ} \mathrm{C}$ a partir de resistência elétrica e termostato.

As taxas de fertilização foram mensuradas 8 horas após o início da hidratação dos ovos, em microscópio estereoscópio (10X), utilizando-se aproximadamente 800 ovos de cada unidade experimental, amostra superior ao mínimo (260 ovos) recomendado por Zaniboni Filho (1992).

Os resultados das taxas de fertilização foram submetidos à análise de variância a 5\% de probabilidade e, em caso de evidência de diferença significativa, foi aplicada a análise de regressão LRP (Linear Response Plateau), também a $5 \%$ de probabilidade. O software utilizado para a realização das análises estatísticas foi o SAEG - Sistema de Análises Estatísticas e Genéticas (UFV, 1997).

\section{Resultados e Discussão}

A temperatura média da água de condicionamento dos reprodutores no período pré ovulatório foi de $22,0 \pm 1,0^{\circ} \mathrm{C}$, valores considerados adequados para a espécie (Gomes et 
al., 2000). Os dados de peso corporal, volume de sêmen e produção relativa de sêmen produzido estão expressos na Tabela 1 .

Os machos produziram grande volume de sêmen em comparação ao observado por Ferreira et al. (2001) e Kavamoto \& Fogli da Silveira (1986), que observaram $0,41 \mathrm{~mL}$ em $R$. quelen e $0,8 \mathrm{~mL}$ em $R$. hilarii, coletados do ambiente natural, respectivamente. A grande produção de sêmen observada pode ser explicada pela aplicação de EHC, pois, segundo Streit Jr. (2002) e Rurangwa et al. (2004), a indução com EHC estimula a produção de sêmen, porém, em menores concentrações espermáticas. De acordo com Luz et al. (2001), o volume de sêmen produzido pelos peixes é muito variável e depende do tamanho do indivíduo, da época e da metodologia de coleta.

A avaliação do índice de sobrevivência espermática pela coloração diferencial (eosina - nigrosina) demonstrou que $96 \%$ das células não foram coradas, ou seja, apresentaram-se vivas. Este resultado é positivo se comparados aos dados de Kavamoto \& Fogli da Silveira et al. (1986), em Rhamdia hilarii, que verificaram média de $86,73 \%$ de células vivas.

Ferreira et al. (2001) verificaram aspecto interessante na motilidade espermática progressiva em machos de Rhamdia quelen induzidos com hormônios, os quais apresentaram maior tempo de movimentação se comparados com machos não induzidos. Este fato pode estar relacionado ao maior índice de sobrevivência dos espermatozóides verificado por esse autor, visto que, provavelmente, a indução tenha provocado maior produção de fluido seminal (HilomenGarcia et al., 2002), o que proporcionou melhores condições aos espermatozóides.

A concentração espermática verificada a partir do pool de sêmen utilizado foi de $1,97 \times 10^{10}$ espermatozóide. $\mathrm{mL}^{-1}$. Este resultado é inferior aos resultados obtidos por Ferreira et al. (2001), em machos da mesma espécie (concentrações de $6,99 \times 10^{10}$ espermatozóides.mL $\mathrm{mL}^{-1}$ ). Fogli da Silveira et al. (1985) e Kavamoto \& Fogli da Silveira (1986) em estudos com Rhamdia hilarii obtiveram média de $6,35 \times 10^{10}$ espermatozóides. $\mathrm{mL}^{-1}$ e $5,58 \times 10^{10}$ espermatozóides. $\mathrm{mL}^{-1}$, respectivamente. Este fato corrobora a hipótese de a indução hormonal aumentar o produção de sêmen. Possivelmente, a reduzida concentração espermática tenha decorrido do alto volume de fluido seminal produzido.

Pela análise da morfologia, verificou-se $66,9 \%$ dos pespermatozóides não apresentaram alterações morfológicas, $5,76 \%$ tiveram alterações consideradas graves (microcefalia, macrocefalia, cauda enrolada, cauda quebrada, cauda degenerada) e 26,34\% apresentaram alterações leves (cauda torta, cabeça solta, cauda solta, gotas citoplasmáticas). Estes resultados são semelhantes aos resultados encontrados por Streit Jr. (2002) no sêmen de pacu (Piaractus mesopotamicus). Esse autor verificou $63 \%$ de espermatozóides normais, $12,4 \%$ com alterações graves e $24,6 \%$ com alterações consideradas leves.

Kavamoto et al. (1999), estudando sêmen de curimbatá (Prochilodus lineatus), verificaram que 9,54\% dos espermatozóides apresentaram alguma alteração morfológica, relacionada à aplicação de hormônios e ao tempo decorrido até a espermiação.

De acordo com o CBRA (1998), índices de alterações morfológicas espermáticas não devem ultrapassar 30\% nos eqüinos e bovinos e $20 \%$ em suínos e ovinos para não prejudicar o índice de fertilidade. Contudo, estes índices ainda são pouco estudados na espécie em estudo, o que dificulta qualquer tipo de comparação.

Contudo, a qualidade geral do sêmen utilizado neste trabalho apresentou-se elevada, sugerindo que estas variáveis não influenciaram de forma negativa as taxas de fertilização.

Os resultados de peso corporal, número total de ovócitos $(\mathrm{O})$ produzidos e produção relativa de ovócitos são apresentados na Tabela 2. Os ovócitos apresentavam diâmetro e cor uniforme. As duas fêmeas apresentaram produção média de 148.102 ovócitos.kg de fêmea ${ }^{-1}$, valores considerados baixos em comparação às afirmações de Gomes et al. (2000), que sugeriram que cada quilo de fêmea de Rhamdia quelen produz, em média, 216.000 ovócitos.

Tabela 1 - Peso corporal, volume de sêmen produzido individualmente por ejaculado de reprodutor e produção relativa de sêmen Table 1 - Body weight, individual semen volume produced by breeder and relative semen production

\begin{tabular}{|c|c|c|c|c|c|}
\hline \multirow[t]{2}{*}{$\begin{array}{l}\text { Variável } \\
\text { Variable }\end{array}$} & \multicolumn{4}{|c|}{$\begin{array}{l}\text { Animal } \\
\text { Animal }\end{array}$} & \multirow[b]{2}{*}{$\begin{array}{l}\text { Média } \\
\text { Mean }\end{array}$} \\
\hline & $\begin{array}{c}\text { Macho } 1 \\
\text { Male } 1\end{array}$ & $\begin{array}{c}\text { Macho } 2 \\
\text { Male } 2\end{array}$ & $\begin{array}{c}\text { Macho } 3 \\
\text { Male } 3\end{array}$ & $\begin{array}{c}\text { Macho } 4 \\
\text { Male } 4\end{array}$ & \\
\hline Peso (g) (Weight, g) & 208 & 177 & 142 & 149 & $169 \pm 30$ \\
\hline Volume de sêmen $(\mathrm{mL})$ (Semen volume) & 6,1 & 5,2 & 5,8 & 6,5 & $5,9 \pm 0,54$ \\
\hline Produção de sêmen $\left(\mathrm{mL}^{-1} \mathrm{~g}^{-1}\right)$ (Semen production) & 0,029 & 0,029 & 0,041 & 0,044 & $0,036 \pm 0,008$ \\
\hline
\end{tabular}


Além disso, as fêmeas utilizadas neste trabalho produziram, a partir do pool de ovócitos, uma média de 1141 ovócitos.g de ovócitos ${ }^{-1}$. Todavia, estes dados podem ser influenciados pela idade das matrizes, a nutrição, a época do ano, o grau de repleção do estômago e os processos hormonais.

Os resultados das taxas de fertilização dos ovócitos de Rhamdia quelen em função das doses inseminantes são expressos na Figura 1.

Os resultados de fertilização apresentaram efeito $(\mathrm{P}<0,05)$ entre os tratamentos, sugerindo um comportamento linear positivo $(\mathrm{P}<0,05)$ até a dose ou a relação de

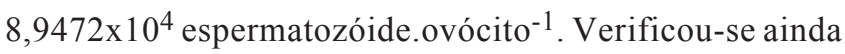
que, a partir desta concentração de espermatozóide.ovócito-1 ${ }^{-1}$, os índices de fertilização alcançaram um plateau, ou seja, não apresentaram efeito $(\mathrm{P}>0,05)$ entre os tratamentos, permanecendo constantes (Figura 1). O ponto de início do plateau, que sugere a dose mínima efetiva, foi correspondente a 89.472 espermatozóide.ovócito ${ }^{-1}$, apresentando taxa de fertilização de $86,68 \%$.

Bart \& Dunham (1996) e Linhart et al. (2004) também evidenciaram o mesmo efeito sobre a taxa de fertilização de ovócitos de Bagre do Canal (Ictalurus punctatus) e Catfish europeu (Silurus glanis), com doses inseminantes de $1,25 \times 10^{5}$ e $8 \times 10^{2}$ espermatozóide.ovócito, respectivamente.

Fogli da Silveira et al. (1988), estudando o efeito da concentração espermática sobre as taxas de fertilização em truta (Salmo irideus), obsevaram que concentrações superiores a $2 \times 10^{5}$ espermatozóides.ovócito ${ }^{-1}$ maximizaram as taxas de fertilização $(80,83 \%$ até $87,60 \%)$. Outros autores verificaram ainda doses inseminantes ideais para outras espécies, como $140 \times 10^{3}$ espermatozóide.ovócito ${ }^{-1}$ para a tilápia (Oreochromis spp.) (Rana \& McAndrew, 1989), $15 \times 10^{3}$ espermatozóide.ovócito para o bagre africano (Clarias garienpinus) (Rurangwa et al., 1998), acima de

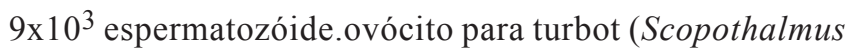

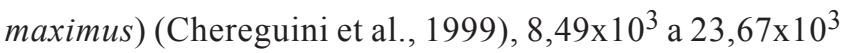

Tabela 2 - Peso corporal, número total de ovócitos (O) produzidos e produção relativa de ovócitos

Table 2 - Body weight, number of total oocytes and relative oocytes production

\begin{tabular}{lcc}
\hline $\begin{array}{l}\text { Variável } \\
\text { Variable }\end{array}$ & \multicolumn{2}{c}{$\begin{array}{c}\text { Animal } \\
\text { Animal }\end{array}$} \\
\cline { 2 - 3 } & $\begin{array}{c}\text { Fêmea 1 } \\
\text { Female 1 }\end{array}$ & $\begin{array}{c}\text { Fêmea 2 } \\
\text { Female 2 }\end{array}$ \\
\hline $\begin{array}{l}\text { Peso corporal (g) } \\
\text { Body weight } \\
\mathrm{n}^{\circ} \text { total de ovócitos } \\
\begin{array}{l}n \text { total of oocytes } \\
\text { Produção relativa }\left(\mathrm{O}^{-1}\right)\end{array}\end{array}$ & 264 & 1038 \\
Relative production & 30.807 & 162.022 \\
\hline
\end{tabular}

espermatozóides.ovócito para a carpa comum (Ciprinus carpio) (Linhart et al., 2003) e $314,428 \times 10^{3}$ espermatozóides.ovócito para a pabanha (Brycon insignis) (Shimoda etal., 2004).

Borsato da Silva (2000), analisando o potencial de fertilização de sêmen criopreservado de curimba (Prochilodus lineatus), verificou que $0,06 \mathrm{~mL}$ de sêmen era suficiente para fertilizar $15 \mathrm{~g}$ de ovócitos, porém, com $20 \mathrm{~g}$ de ovócitos fertilizados com a mesma quantidade se sêmen as taxas de fertilização diminuíram significativamente. Este fato também sugere a existência de uma relação adequada entre número de espermatozóide.ovócitos ${ }^{-1}$ a serem fertilizados para obtenção de bons resultados.

As taxas de fertilização podem sofrer influência do número de espermatozóides para cada ovócito (dose inseminante), do tempo de contato entre os gametas e do protocolo de fertilização empregado (Rurangwa et al., 2004). Especialmente a proporção espermatozóide.ovócito ${ }^{-1}$ adequada para a fertilização apresenta variações entre espécies (Bart \& Dunham, 1996; Rurangwa et al., 1998), que podem estar relacionadas às características dos gametas femininos e masculinos (Ginzburg, 1972; Suquet et al., 1995).

Suquet et al. (1995), estudando turbot (Scophthalmus maximus), verificaram que a dose inseminante ideal, ou ponto de plateau, foi de 6000 espermatozóide.ovócito-1 com $87,3 \%$ de fertilização. Esta espécie necessita de pouca quantidade de sêmen, pois apresentou algumas características como ovócitos pequenos ( $0,91-1,2 \mathrm{~mm})$, sêmen com elevado tempo de ativação e distância percorrida pelos espermatozóides de até $12 \mathrm{~mm}$, enquanto, para carpa, esta distância fica em apenas $4,8 \mathrm{~mm}$ e em trutas $3 \mathrm{~mm}$.

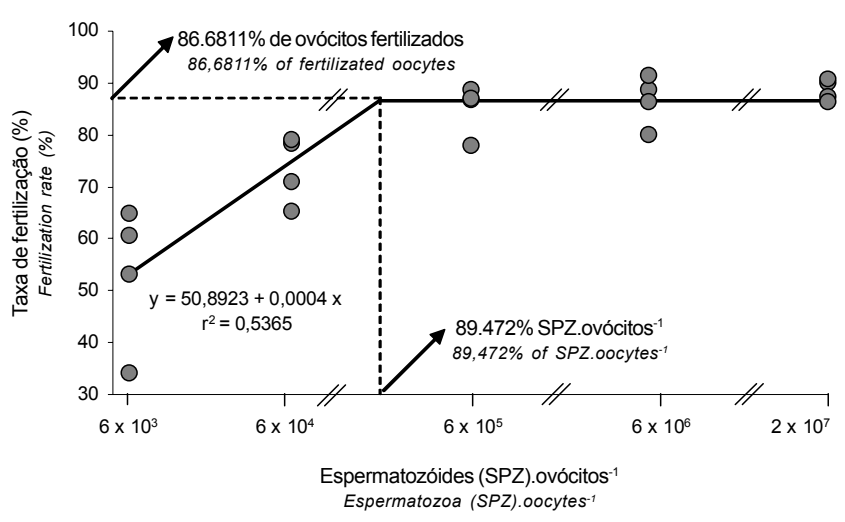

Figura 1 - Fertilização de ovócitos de jundiá cinza (Rhamdia quelen), utilizando-se diferentes relações de espermatozóides:ovócito.

Figure 1 - Oocytes fertilization of grey jundia (Rhamdia quelen) using different spermatozoa:oocyte ratios. 
Analogamente aos resultados de Suquet et al. (1995), quando comparado ao bagre do canal (Ictalurus punctatus), à truta (Salmo irideus) e à tilápia (Oreochromis spp.), o Rhamdia quelen apresenta reduzida taxa de espermatozóide. ovócito ${ }^{-1}$ para atingir índices de fertilização adequados, o que, possivelmente, está relacionado ao tamanho do ovócito, de aproximadamente 1 a 1,3 mm (Gomes et al., 2000). Contudo, outros fatores como o tempo de ativação e a distância percorrida pelo espermatozóide também podem influenciar de modo interespecífico.

Em comparação às outras espécies de peixes que necessitam reduzidas relações espermatozóide.ovócito-1, como o bagre africano (Clarias garienpinus), o turbot (Scopothalmus maximus) e a carpa comum (Cyprinus carpio), o Rhamdia quelen apresenta reduzida capacidade de fertilização, pois o número de espermatozóide necessário para fertilizar um único ovócito é relativamente alto. Contudo, esta relação é necessária desde que cada ovócito tenha apenas um único ponto de penetração, a micrópila, local que, em baixas concentrações, os espermatozóides não podem alcançar (Rurangwa et al., 1998). É provável que o tempo de ativação espermática tenha influência sobre este processo, pois é bastante reduzido para o Rhamdia quelen (1,83 a 2,58 min) (Ferreira et al., 2001) em comparação a outros peixes como o turbot (1 a $17 \mathrm{~min}$ ) (Chereguini et al., 1999), necessitando de um número maior de espermatozóide.

Contrariamente a este experimento, Tvedt et at. (2001) não evidenciaram efeito das doses inseminantes no intervalo de $9 \times 10^{5}$ a $5 \times 10^{8}$ espermatozóides.ovócito ${ }^{-1}$ para o Atlantic halibut (Hippoglossus hipoglossus). Apesar desta inconsistência dos dados, os autores sugeriram que altas taxas de fertilização podem ser alcançadas dentro de um amplo intervalo de doses inseminantes.

O tempo gasto com a manipulação dos gametas masculinos e femininos neste experimento não causou efeito negativo sobre as taxas de fertilização. Evidências contrárias foram verificadas por Huergo (2004), em estudo com triploidia em Rhamdia quelen no qual testou dois controles de fertilização, um antes e outro após os tratamentos e verificou diminuição de 74 para $55 \%$ nas taxas de fertilização ao longo do tempo.

Estudos para otimizar o uso de reprodutores são importantes para o desenvolvimento da aqüicultura, especialmente com espécies nativas brasileiras. Logo, novos estudos devem ser realizados para determinação de doses ideais de sêmen para outras espécies exploradas comercialmente. Além disso, outros parâmetros influentes no processo reprodutivo também devem ser explorados com este fim.

\section{Conclusões}

A quantidade de sêmen, ou dose inseminante, mais eficiente para a espécie jundiá cinza (Rhamdia quelen) foi de 89.472 espermatozóides por ovócito liberado, o que produziu taxa máxima teórica de fertilização de $86,68 \%$.

\section{Literatura Citada}

BALDISSEROTO, B. Biologia do jundiá. In: BALDISSEROTO, B.; RADÜNZ NETO, J. (Eds.). Criação de jundiá. Santa Maria: Editora UFSM, 2004. p.67-72.

BARCELLOS, L.J.G.; KREUTZ, L.C.; RODRIGUES, L.B. et al. Haematological and biochemical characteristics of male jundia (Rhamdia quelen Quoy \& Gaimard pimelodidae): change after acute stress. Aquaculture Research, v.34, p.1465-1469, 2003.

BART, A.N.; DUNHAM, R.A. Effects of sperm concentration and egg number on fertilization efficiency with channel catfish (Ictalurus punctatus) eggs and blue catfish (I. furcatus) spermatozoa. Theriogenology, v.45, p.673-682, 1996.

BILLARD, R.; COSSON, J.; CRIM, L.W. et al. Sperm physiology and quality. In: BROMAGE, N.R.; ROBERTS, R.J. (Eds.) Broodstock management and egg and larval quality. London: Blackwell Science, 1996. p.25-52.

BORSATO DA SILVA, E. Avaliação comparativa da utilização do sêmen criopreservado e fresco na fertilização dos óvulos de curimatá (Prochilodus lineatus) (Valenciennes, 1836). Florianópolis: Universidade Federal de Santa Catarina, 2000. 49p. Dissertação (Mestrado em aqüicultura) - Universidade Federal de Santa Catarina, 2000.

BOSCARDIN BORGHETTI, N.R.; OSTRENSKY, A.; BORGHETTI. J.R. Aqüicultura: uma visão geral sobre a produção de organismos aquáticos no brasil e no mundo. Curitiba: Grupo Integrado de Aqüicultura e Estudos Ambientais, 2003. 128p.

CHEREGUINI, O.; DE LA BANDA, I.G.; RASINES, I. et al. Artificial fertilization in turbot, Scopothalmus maximus, (L.): different methods and determination of the optimal sperm-egg ratio. Aquaculture Research, v.30, p.319-324, 1999.

COLÉGIO BRASILEIRO DE REPRODUÇÃO ANIMAL - CBRA. Manual para exames andrológicos e avaliação de sêmen animal. 2.ed. Belo Horizonte: Colégio Brasileiro de Reprodução Animal, 1998. 49p.

DENNISTON. R.S.; MICHELET, S.; GODKE, R.A. Principles of Cryopreservation. In: TIERSCH, T.R.; MAZIK, P.M. (Eds.). Cryopreservation in aquatic species. Morgantown: The World Aquaculture Society, 2000. p.59-74.

ERDAHL, A.W.; GRAHAM, E.F. Fertility of teleost semen as affected by dilution and storage in a seminal plasma-mimicking medium. Aquaculture, v.60, p.311-321, 1987.

FERREIRA, A.A.; NUÑER, A.P.O.; LUZ, R.K. et al. Avaliação qualitativa e quantitativa do sêmen de jundiá, Rhamdia quelen. Boletim do Instituto de Pesca, v.27, n.1, p.57-60, 2001.

FOGLI DA SILVEIRA, W.; KAVAMOTO, E.T.; NARAHARA, M.Y. Avaliação da qualidade e crio - preservação em forma de "pellets" do sêmen de bagre, Rhamdia hilarii (Valenciennes, 1840), Boletim do Instituto de Pesca, v.12, n.4, p.7-11, 1985.

FOGLI DA SILVEIRA, W.; KAVAMOTO, E.T.; RIGOLINO, M.G. et al. Fertilidade do sêmen de truta arco-íris, Salmo irideus gibbons, em diferentes concentrações de espermatozóides por óvulo. Boletim do Instituto de Pesca, v.15, n.1, p.51-54, 1988.

GINZBURG, A.S. Fertilization in fishes and the problem of polyspermy. Jerusalem: Israel Program for Scientific Traslocation Ltda, 1972. 366p.

GOMES, L.C.; GOLOMBIESKI, J.I.; CHIPPARI GOMES, A.R. et al. Biologia do jundiá Ramdia quelen (teleostei, pimelodidae). Ciência Rural, v.30, p.179-185, 2000. 
HAFEZ, E.S.E; HAFEZ, B. Reprodução animal. 7.ed. Barueri: Manole, 2004. 509p.

HILOMEN-GARCIA, G.V.; BALDEVARONA, R.B.; LACANILAO, F. Milt production of sea bass Lates calcarifer bloch administered an analogue of luteinizing hormone - relesing hormone and 17 $\alpha$-methyltestosterone. The Israeli Journal of Aquaculture, v.54, n.4, p.173-182, 2002.

HUERGO, G.P.C.M. Indução à triploidia no jundiá Rrhamdia quelen, Quoy \& Gaimard, 1824) através do choque de pressão hidrostática. Florianópolis: Universidade Federal de Santa Catarina, 2004. 42p. Dissertação (Mestrado em aqüicultura) - Universidade Federal de Santa Catarina, 2004.

KAVAMOTO, E.T.; FOGLI DA SILVEIRA, W. Características físicas, químicas e microscópicas do bagre, rhamdia hilarri (Valenciennes, 1840) em condições de campo. Boletim do Instituto de Pesca, v.13, p.95-100, 1986.

KAVAMOTO, E.T.; BARNABE, V.H.; CAMPOS, B.E.S. et al. Anormalidades morfológicas nos espermatozóides do curimbatá, Prochilodus scrofa (Steidachner, 1881) (osteichthyes, characiformes, prochilodontidae). Boletim do Instituto de Pesca, v.25, p.61-66, 1999

LINHART, O.; GELA, D.; RODINA, M. et al. Optimization of artificial propagation in European catfish, Silurus glanis L. Aquaculture, v.235, p.619-632, 2004.

LINHART, O.; RODINA, M.; GCLA, D. et al. Improvement of common carp artificial reproduction using enzyme for elimination of eggs stickiness. Aquatic Living Resources, n. 16, p.450-456, 2003

LUZ, R.K.; FERREIRA, A.A.; REYNALTE-TAJATE, D.A. et al. Avaliação qualitativa e quantitativa do sêmen do suruvi, Steindachneridion scripta (pimelodidae). Boletim do Instituto de Pesca, v.27, n.1, p.39-42, 2001.

MARCHIORO, M.I.; BALDISSEROTTO, B. Sobrevivência de alevinos de jundiá (Rhamdia quelen Quoy \& Gaimard, 1824) à variação de salinidade da água. Ciência Rural, v.29, n.2, p.315-318, 1999.

MARQUES, S. Preservação a curto prazo do sêmen de teleósteos neotropicais de água doce. Belo Horizonte: Pontifícia Universidade Católica, 2001. 98p. Dissertação (Mestrado de Zoologia de Vertebrados) - Pontifícia Universidade Católica de Minas Gerais, 2001.

MYLONAS, C.C.; GISSIS. A.; MAGNUS, Y. et al. Hormonal changes in male white bass (Morone chysops) and evaluation of milt quality after treatment with a sustained-release GnRHa delivery system. Aquaculture, v.153, p.301-311, 1997.

NAKATANI, K.; AGOSTINHO, A.A.; BAUMGARTNER, G. et al. Ovos e larvas de peixes de água doce. Maringá: EDUEM, 2001. 378p.

PIAIA, R; BALDISSEROTO, B. Densidade de estocagem e crescimento de alevinos de jundiá Rhamdia quelen (quoy \& gaimard, 1824). Ciência Rural, v.30, n.3, p.509-513, 2000.

RANA, K.J.; MCANDREW, B.J. The viability of cryopreserved tilapia spermatozoa. Aquaculture, v.76, n.3-4, p.335-345, 1989.

RICHARDSON, G.F.; MILlER, T.L.; MCNIVEM, M.A. Cryopreservation of arctic charr (Salvelinus alpinus) (L), semen in various extenders and in three sizes of straw. Aquaculture Research, v.31, p.307-315, 2000.
RITAR, A.J. Artificial insemination with cryopreserved sêmen from striped trumpeter (Latris lineata). Aquaculture, v.180, p.177$187,1999$.

RURANGWA, E.; KIME, D.E.; OLLEVIER, F. et al. The measurement of sperm motility and factors affecting sperm quality in cultured fish. Aquaculture, v.234, p.1-28, 2004.

RURANGWA, E.; ROCLANTS, I.; HUYSKENS, G. et al. The minimum effective spermatozoa:egg ratio for artificial insemination and the effects of mercury on sperm motility and fertilization ability in (Clarias gariepinus). Journal of Fish Biology, v.53, p.402-413, 1998 .

SHIMODA, E.; ANDRADE, D.R.; VIDAL JR., M.V. et al Determinação de razão ótima de espermatozóides por ovócito da piabanha Brycon insignis. In: SIMPÓSIO MERCOSUL DE AQUICULTURA - AQUIMERCO, Vitória, 2004. Anais... Vitória: Sociedade Brasileira de Aqüicultura e Biologia Aquática - Aquabio, 2004. p.212.

SILFVERGRIP, A.M.C. A sistematic revision of the neotropical catfish genus Rhamdia (teleostei, pimelodidae). Stockholm: Swedish Museum of natural History Sweden, 1996. 156p. Thesis (Doctorship in Zoology) - Swedish Museum of natural History, 1996.

STREIT JR., D.P. Extrato de hipófise de frango e de coelho como indutores gonadais de pacu (Piaractus mesopotamicus) macho e fêmea, em comparação com extrato de carpa Maringá: Universidade Estadual de Maringá, 2002. 38p. Dissertação (Mestrado em Zootecnia) - Universidade Estadual de Maringá, 2002.

SUQUET, M.; BILLARD, R.; COSSON, J. et al. Artificial insemination in turbot (Scophthalmus maximus) : determination of the optimal sperm to egg ratio and time of gamete contact. Aquaculture, v.133, p. 83-90, 1995.

TVEDT, H.B.; BENFEY, T.J.; MARTIN-ROBICHAUD, D.J. et al. The relationship between sperm density, spermatocrit, sperm motility and fertilization success in Atlantic halibut, hippoglossus hippoglossus. Aquaculture, v.194, p.191-200, 2001.

UNIVERSIDADE FEDERAL DE VIÇOSA - UFV. SAEG - Sistema para análises estatísticas e genéticas. Versão, 7,1. Viçosa: UFV, 1997. 150p. (Manual do usuário).

WOYNAROVICH, E.; HORVATH, L. A propagação artificial de peixes de águas tropicais: manual de extensão. Brasília: Escopo. 1983. 220p. Tradução de Vera Lucia Mixtra Chama de "The Artificial Propagation of Warm - Water Finfishes - A Manual for Extension".

ZANIBONI FILHO, E. Incubação, larvicultura e alevinagem do tambaqui (colossoma macropomum Cuvier 1818). São Carlos: Universidade Federal de São Carlos, 1992. 202p. Tese (Doutorado em Ecologia de Recursos Naturais) - Universidade Federal de São Carlos, 1992
Recebido: 24/08/05 Aprovado: 24/02/06 